\title{
pH RESPONSIVE DECOMPOSABLE LAYER-BY-LAYER NANOFILMS AND \\ CAPSULES ON THE BASIS OF TANNIC ACID
}

Tatsiana Shutava*, Malcolm Prouty, Dinesh Kommireddy, Yuri Lvov*

Institute for Micromanufacturing and Chemistry Department, Louisiana Tech University, Ruston, LA 71272

\section{Supporting Information}
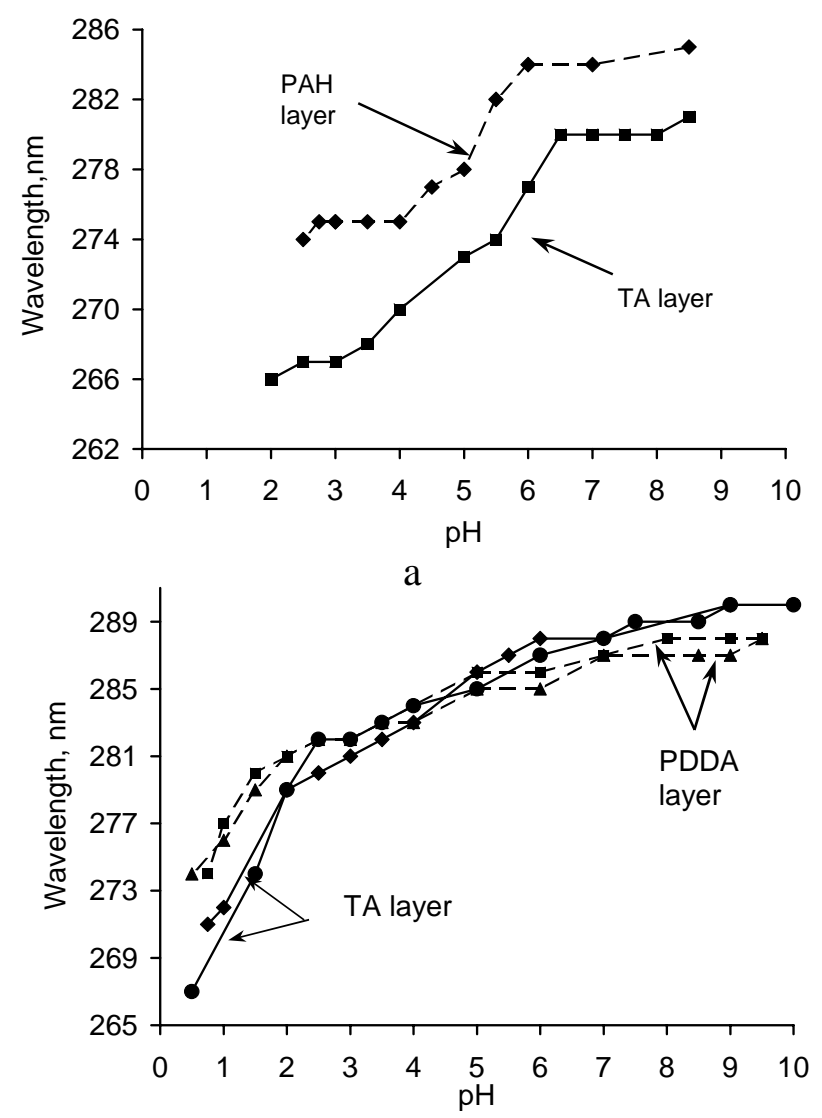

b

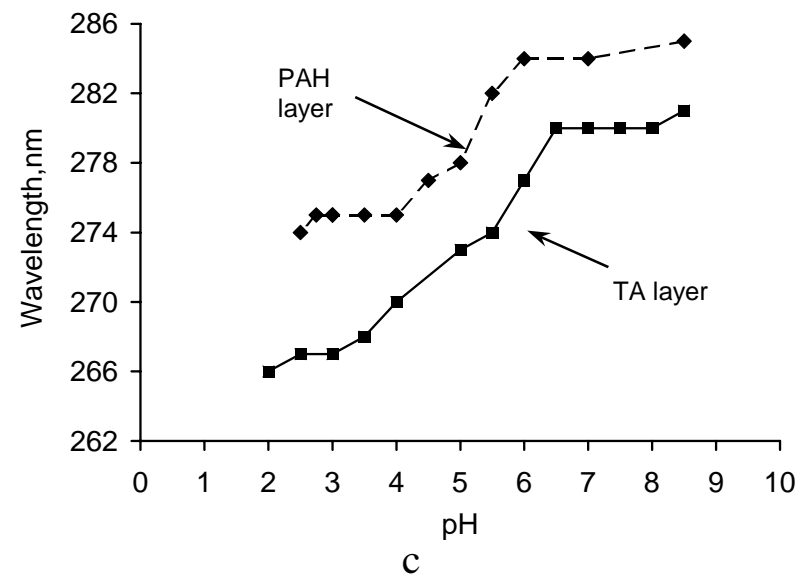

Figure A. Shift of absorbance maximums of the neutral form of TA at different $\mathrm{pH}$ : a $0.0375 \mathrm{mg} / \mathrm{mL}$ TA solution, b - (PDDA/TA $)_{6-6.5}$ films; c - (PAH/TA) $6-6.5$ films. The film outermost layers are indicated on the graphs. 